\title{
ARTICLES
}

\section{Wnt5a Is Required for Cardiac Outflow Tract Septation in Mice}

\author{
J. ROBERT SCHLEIFFARTH, ANTHONY D. PERSON, BRAD J. MARTINSEN, DAVID J. SUKOVICH, ANN NEUMANN, \\ CLARE V.H. BAKER, JAMIE L. LOHR, DAVID N. CORNFIELD, STEPHEN C. EKKER, AND ANNA PETRYK
}

\begin{abstract}
Departments of Pediatrics [J.R.S., B.J.M., D.J.S., A.N., J.L.L., D.N.C., A.P.], Genetics, Cell Biology and Development [A.D.P., SCE., A.P.], Surgery [D.N.C.], and Physiology [D.N.C.], and Arnold and Mabel Beckman Center for Transposon Research [S.C.E.], University of Minnesota, Minneapolis, Minnesota 55455; Department of Physiology, Development, and Neuroscience [C.V.H.B.], University of Cambridge, Cambridge CB2 3DY, United Kingdom
\end{abstract}

\begin{abstract}
Lack of septation of the cardiac outflow tract (OFT) results in persistent truncus arteriosus (PTA), a form of congenital heart disease. The outflow myocardium expands through addition of cells originating from the pharyngeal mesoderm referred to as secondary/anterior heart field, whereas cardiac neural crest (CNC) cellderived mesenchyme condenses to form an aortopulmonary septum. We show for the first time that a mutation in Wnt5a in mice leads to PTA. We provide evidence that Wnt $5 a$ is expressed in the pharyngeal mesoderm adjacent to CNC cells in both mouse and chicken embryos and in the myocardial cell layer of the conotruncus at the time when $\mathrm{CNC}$ cells begin to form the aortopulmonary septum in mice. Although expression domains of secondary heart field markers are not altered in Wnt5a mutant embryos, the expression of CNC cell marker PlexinA2 is significantly reduced. Stimulation of CNC cells with Wnt5a protein elicits $\mathrm{Ca}^{2+}$ transients, suggesting that $\mathrm{CNC}$ cells are capable of responding to Wnt5a. We propose a novel model in which Wnt5a produced in the OFT by cells originating from the pharyngeal mesoderm signals to adjacent $\mathrm{CNC}$ cells during formation of the aortopulmonary septum through a noncanonical pathway via localized intracellular increases in $\mathrm{Ca}^{2+}$. (Pediatr Res 61: 386-391, 2007)
\end{abstract}

$\mathrm{C}^{\mathrm{s}}$ ongenital heart disease is a highly prevalent human disorder occurring in approximately $1 \%$ of live-born infants, $10 \%$ of stillbirths, and $20 \%$ of spontaneous abortions. Cardiac OFT defects account for up to one third of congenital heart disease cases $(1,2)$. Apart from DiGeorge or 22q11.2 deletion syndrome, which is one of the most recognized human syndromes with conotruncal anomalies (3), the etiology of the majority of major cardiac OFT defects remains unknown.

Received June 30, 2006; accepted November 21, 2006

Correspondence: Anna Petryk, M.D., University of Minnesota, Department of Pediatrics, 13-124 PWB, MMC404, 516 Delaware Street SE, Minneapolis, MN 55455; e-mail: petry005@umn.edu

This work was supported by Minnesota Medical Foundation Research Grant to A.P. and J.R.S., R01GM55877 to S.C.E., Vikings Children's Fund Grant to B.J.M. (GIA0902) and J.L.L. (FA-5.03-2), a gift from the Sit Investment Associates Foundation to J.L.L., NIH T32 Postdoctoral Training Fellowship to A.D.P., and Lillehei Heart Institute Research Grant and Howard Hughes Fellowship to J.R.S.

Both J.R.S. and A.D.P. contributed equally to this work.

DOI: $10.1203 /$ pdr.0b013e3180323810
Separation of the pulmonary circulation from the systemic circulation is a crucial step in the development of the mature heart. Proper formation of the OFT is largely dependent on the contribution of two types of cells of mesodermal and CNC origin $(4,5)$. Growth of the outflow myocardium occurs through addition of cells originating from the pharyngeal mesoderm referred to as secondary/anterior heart field (5-7), whereas CNC cell-derived mesenchyme condenses to form an aortopulmonary septum $(4,8,9)$. CNC cells may also indirectly affect addition of the myocardium to the OFT from the secondary heart field $(10,11)$.

Ablation of premigratory $\mathrm{CNC}$ cells in chick embryos results in a spectrum of distinct cardiac OFT phenotypes, including PTA, interruption of the aortic arch, tetralogy of Fallot, and double-outlet right ventricle (12-14). A similar spectrum of phenotypes is observed in humans $(1,2)$ as well as mice with OFT defects. For example, mice deficient in Semaphorin 3C (Sema3C) have PTA due to failure of targeted CNC cell migration (15). Sema3C is a secreted ligand that is expressed in the conotruncus in cells adjacent to migrating CNC cells and is thought to serve as a cue to guide CNC cells to the OFT $(14,15)$. Mice with neural crest cell-specific deletion of type II transforming growth factor $\beta$ (TGF- $\beta$ ) receptor also have PTA (16), but the etiology is less clear, partly because the underlying processes that are responsible for organizing CNC cells into the aortopulmonary septum are poorly understood.

It has been suggested that due to their physical proximity, mesodermal cells of secondary/anterior heart field origin and $\mathrm{CNC}$ cells are likely to interact through signaling mechanisms (5), but the nature of these interactions is unknown. Positional information in developing organisms is frequently determined by morphogenetic gradients, such as those generated by Wnt family of secreted glycoproteins (17). Activation of a Wnt signaling pathway requires interaction between Wnt, a sevenpass transmembrane receptor protein, Frizzled $(\mathrm{Fz})$, lowdensity lipoprotein receptor-related protein (18), and receptor tyrosine kinase Ror2 (19).

Abbreviations: CNC, cardiac neural crest; OFT, outflow tract; PTA, persistent truncus arteriosus; Sema3C, Semaphorin 3C 
Table 1. Distribution of outflow tract and aortic arch defects in Wnt5a $a^{-1-}$ mice

\begin{tabular}{cc}
\hline $\begin{array}{c}\text { Histology only } \\
(n=6)\end{array}$ & $\begin{array}{c}\text { Angiogram } \\
(n=13)\end{array}$ \\
\hline PTA $(n=5)$ & PTA $(n=12)$ \\
& Interruption of the aortic arch $(n=5)$ \\
& Right-sided aortic arch $(n=3)$ \\
& Coarctation of the aorta $(n=2)$ \\
& No associated aortic arch defects $(n=2)$ \\
& Transposition of the great arteries $(n=1)$ \\
Double-outlet right & \\
ventricle $(n=1)$ &
\end{tabular}

The role for Wnt signaling pathway in cardiac development has been suggested by reports showing Fz2 expression in the developing cardiac OFT (20) and the presence of a ventricular septal defect in Ror $2^{-1-}$ mice (19). In this report, we examine the consequences of Wnt5a functional deletion with respect to the formation of the cardiac OFT. Molecular and morphologic analyses are consistent with a model in which Wnt5a signal originating from the pharyngeal mesoderm is instructive to CNC cells during formation of the aortopulmonary septum through a noncanonical $\mathrm{Wnt} / \mathrm{Ca}^{2+}$ pathway.

\section{MATERIALS AND METHODS}

Genotyping of mice. The Wnt $5 a^{+/-}$mice were generously provided by Dr. Andrew McMahon (Harvard University) (21). Embryos used in this study were obtained by intercrossing $W n t 5 a^{+/-}$mice. Wild-type littermates were used as controls. Genomic DNA was polymerase chain reaction (PCR) amplified as described (17). The study was approved by the University of Minnesota Animal Care and Use Committee.

India ink injections. Mouse embryos were collected at E17.5 and dilute (1:100) India ink was injected into the left ventricle and perfused through the vascular system using a microinjector (Medical System Corp. PLI-100) (22).

Histology. Mouse embryos were harvested between E13.5 and E17.5, fixed in $4 \%$ paraformaldehyde, dehydrated through alcohols, embedded in paraffin, and cut into $9-\mu \mathrm{m}$ thick sections. Standard hematoxylin and eosin staining was performed.

In situ hybridization. In situ hybridization was performed on whole mouse and chick embryos as well as paraffin-embedded mouse tissue sections by standard methods (23,24). PlexinA2 (25), Fgf8 (26), Fgflo (27), and Tbx1 (28) probes have been previously described. Crabpl cDNA probe fragment was PCR amplified from a cDNA library obtained from E9.5 embryos (forward: $5^{\prime}$-acccgtccgcagcagaggtg- $3^{\prime}$; reverse: $5^{\prime}$-ggcaacaagagctgaggggag- $3^{\prime}$ ). Sox 10
cDNA probe was amplified from I.M.A.G.E clone ID3675437 (forward: $5^{\prime}$-tgtgtgccctgctcctcatcag-3'; reverse: $5^{\prime}$-ggcagcgatgtgttacatgtgg- $3^{\prime}$ ). cDNA for mouse Wnt-5a (bp 691-1236; GenBank No. NM009524) was isolated by reverse transcriptase PCR from whole E11.5 embryos. Chicken Wnt5a cDNA probe was a 529-bp fragment (NCBI accession No. AB006014) amplified from total $\mathrm{HH}$ stage 16 chicken RNA (forward: 5' -aatggcttctcagtacctcg-3'; reverse: $5^{\prime}$-agcggtatccgtactcgatg- $\left.3^{\prime}\right)$. All in situ hybridization analyses were performed in at least three embryos per probe at a given developmental stage.

Quail-chick CNC chimeras. Quail-chick CNC chimeras were generated as previously published $(24,29)$. In situ hybridization was followed by immunohistochemistry with QCPN (quail nuclei marker) (24,29). The secondary antibody for QCPN was Alexa Fluor 568 rabbit anti-mouse IgG $(\mathrm{H}+\mathrm{L})$ (Molecular Probes) diluted 1:100. The QCPN supernatants were generated from hybridoma cells (obtained from the DSHB, University of Iowa). Chimeras $(n=3)$ were analyzed at embryonic d 2.5-3.0 (HH17/18).

Neural crest outgrowth cultures. Neural folds were isolated in the chick at $\mathrm{HH}$ stage 9-10 from the level of the otic placode to the third somite using a tungsten needle. The neural folds were plated on fibronectin-coated $22 \mathrm{~mm}^{2}$ glass coverslips (BD Biosciences) and cultured for 48 h (29,30). Immunohistochemistry (24) was performed using monoclonal antihuman CD57/HNK-1 antibody (1:100, Sigma Chemical Co.), Alexa Flour 568 goat antimouse IgM (1:100, Molecular Probes), and DAPI (1:200, Molecular Probes)

Calcium imaging. Calcium imaging was performed in individual CNC cells after $48 \mathrm{~h}$ in culture. To assess dynamic changes in cytosolic $\mathrm{Ca}^{2+}$ concentration $\left(\left[\mathrm{Ca}^{2+}\right]_{\mathrm{i}}\right)$, we used the $\mathrm{Ca}^{2+}$-sensitive fluorophore fura-2 AM (Molecular Probes) as previously published (31,32). To determine the effects of the recombinant mouse Wnt3a and Wnt5a proteins (R\&D Systems), along with human endothelin-1 (Et-1, Sigma Chemical Co.) on CNC cell $\left[\mathrm{Ca}^{2+}\right]_{\mathrm{i}}$, baseline measurements were obtained for $5 \mathrm{~min}$ before the substances were superfused over the cells. Wnt3a and Wnt5a were administered to the cells in concentrations ranging from $0.005 \mu \mathrm{g} / \mathrm{mL}$ to $0.05 \mu \mathrm{g} / \mathrm{mL}$ for Wnt5a and $0.005 \mu \mathrm{g} / \mathrm{mL}$ to $0.1 \mu \mathrm{g} / \mathrm{mL}$ for Wnt3a. Et-1 was administered to cells in concentrations ranging from $1 \times 10^{-9} \mathrm{M}$ to $1 \times 10^{-8} \mathrm{M}$.

Statistical analysis. Calcium imaging data are presented as means \pm SEM from three independent experiments. Statistical significance was tested with a $t$ test. Experiments were designed to have a statistical power of $90 \%$ at a probability level of $p<0.05$.

\section{RESULTS}

Wnt5a mutant mice have cardiac OFT abnormalities. $W n t 5 a^{-1-}$ mice are grossly abnormal and die shortly after birth due to multiple defects (21). To assess the cardiac anatomy in these mice, we analyzed 19 mutants by angiographic imaging and/or histologic analysis (Table 1). We found a $100 \%$ penetrance of cardiac OFT abnormalities in Wnt5 $a^{-1-}$ mice $(n=19)$, including PTA $(n=17)$ (Fig. $1 E-H, J)$, double-outlet right ventricle ( $n=1$, not shown), and

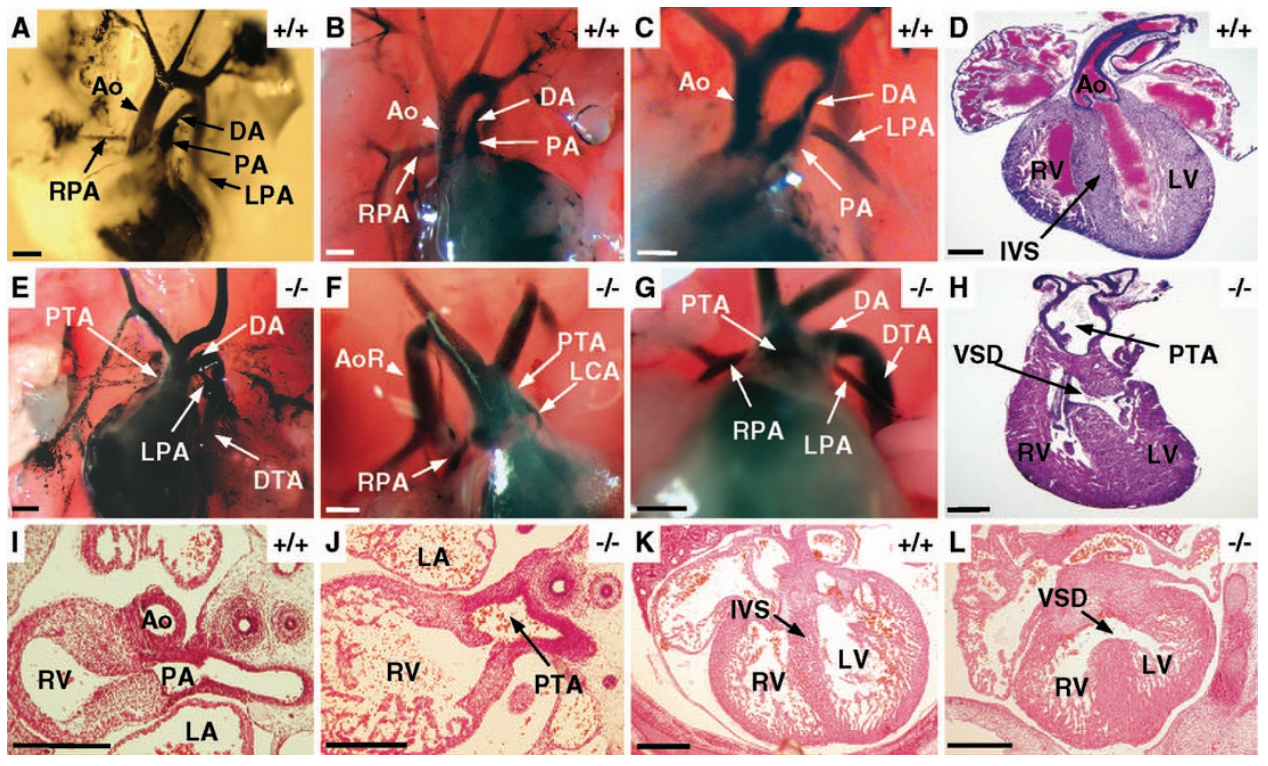

Figure 1. Cardiac angiograms and histologic examination. $(A-C)$ Wild-type OFT with a distinct aorta (Ao) and main pulmonary artery (PA) at E17.5. (D) Coronal section through a heart shown in $C$. $(E)$ PTA with interruption of the aortic arch (IAA) in a mutant at E17.5. (F) Rightsided aortic arch (AoR) in a Wnt5a $a^{-1-}$ embryo at E17.5. $(G)$ PTA with IAA in a $W n t 5 a^{-1-}$ embryo at E17.5. (H) Oblique section through a heart shown in $G$ (atria have been removed). (I) Wild-type OFT at E13.5. ( $J$ ) PTA in a Wnt5a $a^{-1-}$ embryo at E13.5. (K) Wild-type interventricular septum at E13.5. ( $L$ ) VSD in a mutant at E13.5. DA, ductus arteriosus; DTA, descending thoracic aorta; IVS, interventricular septum; LA, left atrium; LCA, left coronary artery; LPA, left pulmonary artery; LV, left ventricle; RPA, right pulmonary artery; RV, right ventricle; VSD, ventricular septal defect. Scale bar, $0.3 \mathrm{~mm}$. 


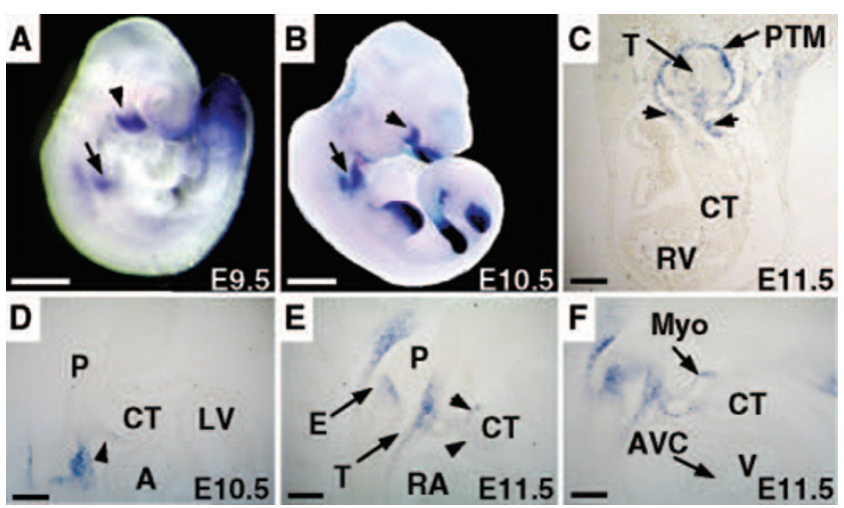

Figure 2. Expression of Wnt5a in wild-type mouse embryos. (A, $B$ ) Expression of Wnt5a in the pharyngeal mesoderm (arrows) at E9.5 (A) and E10.5 (B). Arrowheads point to the first branchial arch. (C) Expression of Wnt5a in the paratracheal mesenchyme (PTM) at E11.5. Wnt5a-expressing cells are seen in the conotruncus (CT, arrowheads). (D) Expression of Wnt5a at E10.5 in cells of the conotruncus (arrowhead). (E, F) Expression of Wnt5a at E11.5 in paraesophageal and paratracheal mesenchyme and the myocardial cell layer of the conotruncus (arrowheads in E). A, atrium; AVC, atrioventricular canal cushion; E, esophagus; LV, left ventricle; Myo, myocardium; P, pharynx; RV, right ventricle; T, trachea; $\mathrm{V}$, ventricle. Scale bar, $0.5 \mathrm{~mm}(A, B) ; 0.2 \mathrm{~mm}$ $(C-F)$.

transposition of the great arteries (TGA) ( $n=1$, not shown). A large subarterial ventricular septal defect (VSD) was present in all specimens (Fig. 1H,L). TGA and VSD, but not PTA, have previously been reported in Ror 2 and Wnt5a null mice (19). In addition to PTA, angiographic analysis revealed other associated aortic arch abnormalities, including interruption of the aortic arch $(n=5 / 12$, Fig. $1 E, G)$, right-sided aortic arch $(n=3 / 12$, Fig. $1 F)$, and coarctation of the aorta $(n=$ $2 / 12$, not shown).

Wnt5a is expressed in the pharyngeal mesoderm. In addition to previously published data (21), we found strong Wnt5a expression in pharyngeal mesoderm in mouse embryos at E9.5 and E10.5 (Fig. 2A,B). No detectable level of Wnt5a expression was present in migrating streams of $\mathrm{CNC}$ cells. Analysis of Wnt5a expression in tissue sections at E10.5 and E11.5 showed that Wnt5a was expressed in paratracheal and parapharyngeal mesenchyme (Fig. 2C,E,F). Wnt5a-expressing cells were also seen in the myocardial cell layer of the conotruncus as early as E10.5 (Fig. 2D) and even more so at E11.5 (Fig. 2E,F).

Expression of Wnt5a at early stages of chicken embryo development was previously shown to be present in the primitive streak and the posterior mesoderm (33). At HH stage 16, there is Wnt5a expression in the branchial arches and pharyngeal mesenchyme in the region consistent with the secondary heart field (Fig. $3 A$ ), similar to the expression pattern in mice (Fig. 2A,B). At stage 17/18, Wnt5a expression is visible in the branchial arches, pharyngeal mesoderm, and contiguous conotruncal mesoderm (Fig. 3B,C).

To definitively determine whether Wnt5a is expressed in the $\mathrm{CNC}$ cells, we used quail-chick CNC chimeras. Wnt5a was not expressed in migrating quail $\mathrm{CNC}$ cells, but rather in the pharyngeal mesenchyme adjacent to migrating neural crest cells at HH17/18 (Fig. 3D,F), consistent with the expression
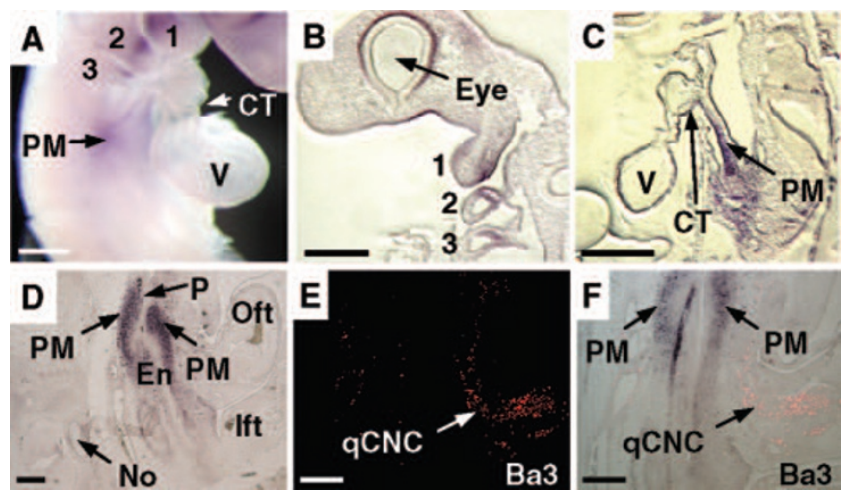

Figure 3. Expression of $W n t 5 a$ in chicken embryos and CNC quail-chick chimeras. (A) Expression of Wnt5a in branchial arches (1-3) and pharyngeal mesenchyme (PM) at HH16. Wnt5a expression at HH17/18 in (B) branchial arches, $(C)$ pharyngeal mesenchyme, contiguous conotruncal mesoderm, and the ventricular wall. $(D-F)$ Quail-chick chimeras; parasagittal sections of a chick host collected at E2.5-3.0. (D) Wnt5a (blue) is expressed in the pharyngeal mesenchyme. (E) QCPN (quail nuclei marker, red) marks quail CNC grafted cells migrating through the third branchial arch (ba3). (F) Same section as shown in $E$; merged images of Wnt5a and QCPN immunostaining show that the migrating quail CNC cells are not expressing Wnt5a. CT, conotruncus; En, pharyngeal endoderm; Ift, inflow tract; P, pharynx; No, notochord; V, ventricle. Scale bar, $0.3 \mathrm{~mm}$.

pattern in mouse embryos (the ability of chick Wnt5a probe to detect quail Wnt5a mRNA was confirmed in quail embryos, data not shown).

Expression domains of secondary heart field markers are not altered in Wnt5a ${ }^{-1-}$ mice. To determine whether the development of the secondary/anterior heart field itself is affected in Wnt5a mutants, we used markers that have previously been shown to be expressed in the region of the pharyngeal mesoderm: Fgf8, FgflO, and Tbxl (34). All three genes were expressed in partially overlapping domains in wild-type embryos (Fig. 4A,C,E). By comparison, the expression of Wnt5a was confined to the caudal region of pharyngeal mesoderm (Fig. 2A). The expression of Fgf8, FgflO, and TbxI was not altered in Wnt5a mutants, arguing against a lack of formation of the secondary/anterior heart field (Fig. 4B,D,F).

Expression of CNC marker PlexinA2 is significantly reduced in Wnt5a mutant mice. Because deficiencies in the CNC cells lead to cardiac OFT defects (1), we examined the effect of functional deficiency of Wnt5a on the expression of neural crest markers that are present in populations of migrating neural crest cells, including Sox10 (35) and Crabpl (36). The expression of both markers in Wnt5a ${ }^{-1-}$ mice was indistinguishable from that of their wild-type littermates, suggesting that the initial migration of CNC cells was normal (Fig. $4 G-J)$. However, the expression of a CNC cell-specific marker, PlexinA2 (15,37), at the time when CNC cell-derived mesenchyme condenses to form an aortopulmonary septum, was markedly reduced in mutant mice (Fig. $4 L$ ). This suggests that lack of proper contribution of CNC cells to the forming aortopulmonary septum may account for the cardiac phenotypes observed in $W n t 5 a^{-1-}$ mice. Proliferation and apoptosis were examined using methods similar to those described by Choudhary et al. (16) and did not reveal any significant differences between wild-type and mutant mice (data not shown). 


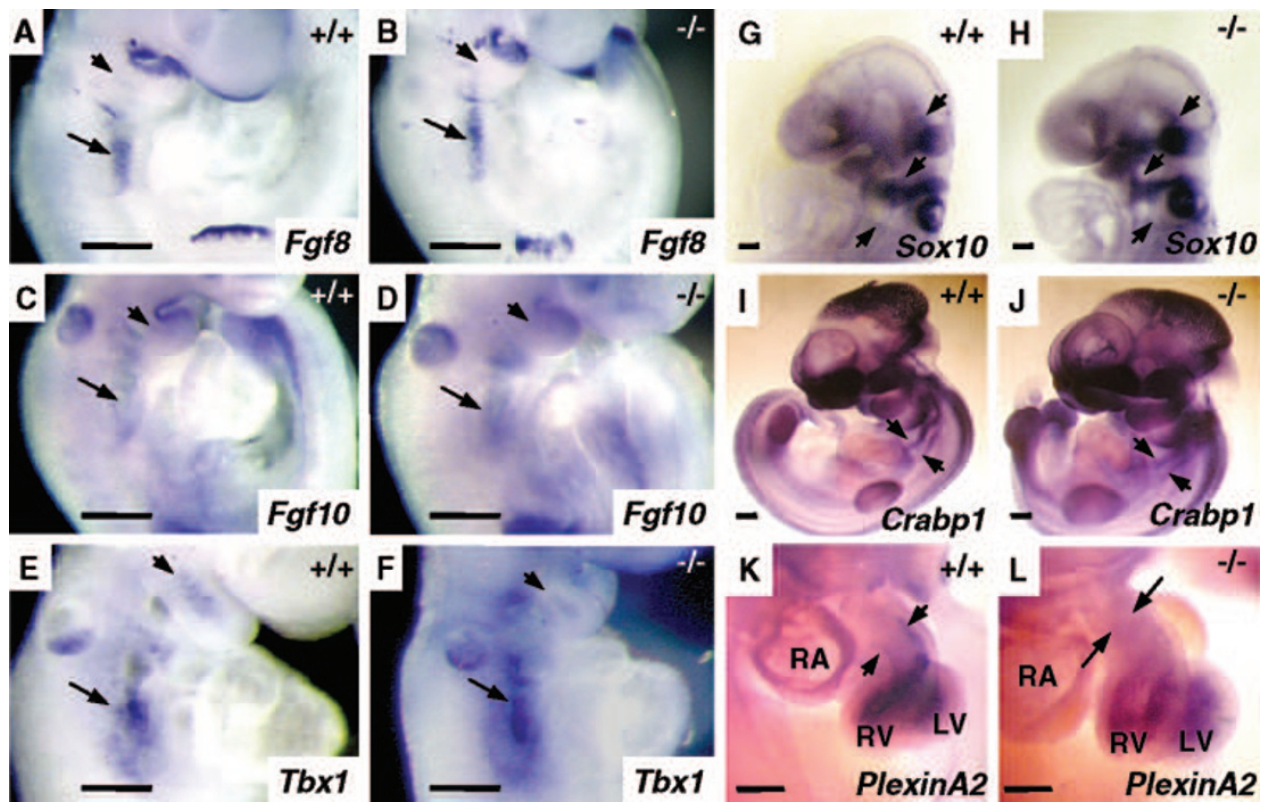

Figure 4. Expression of secondary heart field and neural crest cell markers. $(A-F)$ Expression domains of secondary heart field markers are not altered in Wnt $5^{-1}$ mice compared with wild-type mice at E9.5: $F g f 8(A, B), F g f 10(C, D), T b x 1(E$, $F)$. The arrows point to the pharyngeal mesoderm and arrowheads to the first branchial arch. $(G-L)$ Expression of neural crest cell markers. Sox10 at E9.5 $(G, H)$, Crabpl at E10.5 $(I, J)$. Streams of neural crest cells (arrowheads) are present in both wild-type and Wnt5a $a^{-1-}$ embryos. $(K, L)$ PlexinA2 at E11.5. $(K)$ Two prongs of PlexinA2 expression (arrowheads) in the OFT of wild-type mice. (L) Significantly reduced expression of PlexinA2 (arrows) in Wnt5a mutant mice. RV, right ventricle; LV, left ventricle; RA, right atrium. Scale bar, $0.3 \mathrm{~mm}$.

Stimulation with Wnt5a protein elicits $\mathrm{Ca}^{2+}$ transient in CNC cells. Wnt5a is a founding member of the noncanonical subclass of Wnts, which is thought to signal through either a planar cell polarity pathway or a $\mathrm{Ca}^{2+}$ pathway (38). To begin to understand how Wnt5a may signal to CNC cells, we measured the effect of exogenous Wnt5a protein on $\mathrm{Ca}^{2+}$
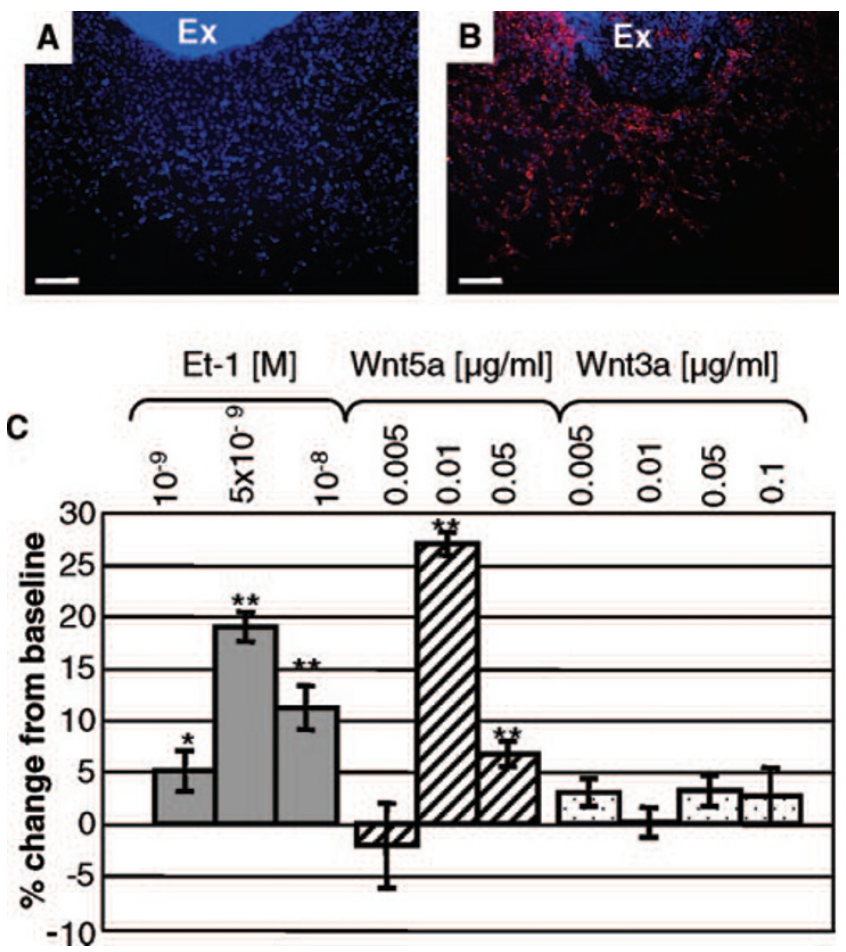

Figure 5. Calcium transients in chick CNC cells. $(A)$ Negative control (no CD57/HNK-1 antibody), DAPI staining. (B) Overlay of HNK-1 and DAPI staining. Cells expressing HNK-1 have migrated away from the explant (Ex). (C) The effects of Et-1, Wnt5a, and Wnt3a on cytosolic calcium concentrations in CNC cells. Et- 1 increased $\left[\mathrm{Ca}^{2+}\right]_{\mathrm{i}}$ in $\mathrm{CNC}$ cells by $18.9 \pm$ $1.44 \%$ and Wnt5a by $26.9 \pm 1.1 \%$ compared with baseline. There was no response after addition of Wnt3a to the cells. $* p<0.01$, $* * p<0.001$. Scale bar, $0.2 \mathrm{~mm}(A, B)$. transients in chick CNC cells in vitro (Fig. 5C), and compared its effects to those elicited by Wnt3a (a member of the canonical Wnt pathway) and Et-1 (Et-1 receptor is expressed in the neural crest cells) (39). The cells that were exposed to Wnt5a were positive for HNK-1 (Fig. 5B).

Wnt5a increased $\left[\mathrm{Ca}^{2+}\right]_{\mathrm{i}}$ in CNC cells that migrated from the explant by $26.9 \pm 1.1 \%$ at a dose of $0.01 \mu \mathrm{g} / \mathrm{mL}(n=57$ cells, $p<0.001)$, whereas Et- 1 increased $\left[\mathrm{Ca}^{2+}\right]_{\mathrm{i}}$ by $18.9 \pm$ $1.44 \%$ at a concentration of $5 \times 10^{-9} \mathrm{M}(n=38$ cells, $p<$ 0.001) (Fig. 5C). The addition of Wnt3a had no significant effect on CNC cell $\left[\mathrm{Ca}^{2+}\right]_{\mathrm{i}}$ even at a concentration twice as high as that of Wnt5a protein $(n=22$ cells $)$.

\section{DISCUSSION}

Septation of the cardiac OFT and remodeling of aortic arch arteries requires $\mathrm{CNC}$ cells (40). Ablation of the $\mathrm{CNC}$ in chick embryos produces abnormal cardiac OFT phenotypes including PTA, interruption of the aortic arch, and double-outlet right ventricle (12). Although interrupted aortic arch is a more indirect result of neural crest apoptosis and their contribution to smooth muscle (16), formation of the aortopulmonary septum is entirely dependent on CNC cells. In this report, we show a similar spectrum of cardiac OFT phenotypes in Wnt5a mutant mice, suggesting lack of proper contribution of CNC cells to OFT formation in these mice.

Wnt $5 a$, however, is not expressed in CNC cells, but rather in the pharyngeal mesoderm. This area has been referred to in the literature as either the anterior heart field or the secondary heart field. It is not clear, at present, whether these two areas are distinct or overlapping $(5,41)$. The anterior heart field is thought to contribute to the right ventricle, conus, and truncus in the mouse $(7,42)$, whereas the secondary heart field is more restricted and contributes only to the arterial pole (mostly truncus) and not to the right ventricle and conus in the chick $(6,40)$. Wnt5a expression is restricted to the pharyngeal mesoderm caudal to the OFT. Lack of specific molecular markers 
limits the ability to precisely distinguish between the anterior and secondary heart field. Mutations in the genes expressed in the anterior heart field would be expected to result in the loss of the entire outflow limb, including the right ventricle, as has been described in mice that are homozygous null for Isl-I (43). The observation that the expression of secondary/ anterior heart field markers is largely unaltered in $W n t 5 a^{-1-}$ mice argues against a global defect in secondary/anterior heart field formation, but rather suggests defective signaling from the pharyngeal mesoderm to CNC cells.

Proper formation and septation of the OFT depends on the concerted movements of pharyngeal mesodermal cells and CNC cells as the OFT moves caudally along the ventral pharynx (11). The morphogenetic events that lead to the final assembly and septation of the cardiac OFT are poorly understood (16). It is conceivable that Wnt5a produced within the OFT by the cells of mesodermal origin is important for establishing a normal local environment for the incoming CNC cells that will populate and condense to form the aortopulmonary septum. Interestingly, Fz2, which can function as a receptor for Wnt5a, is also expressed in the OFT (20). The interaction between mesodermal and $\mathrm{CNC}$ cells would be conceptually analogous to the regulation of insulin-positive cell migration in vertebrate pancreas (17). Wnt5 and $F z 2$ are expressed in the mesodermal cells adjacent to migrating insulin-positive cells in zebrafish embryos, thereby providing the right environment and/or directional signals to insulin-positive cells so that they can coalesce to form an islet.

Our experiments with $\mathrm{Ca}^{2+}$ transients demonstrate that $\mathrm{CNC}$ cells are capable of responding to Wnt5a. One possibility is that Wnt5a may provide positional information for CNC cells during the final step of their targeted migration to the OFT. Impaired targeted migration (evidenced by reduced PlexinA2 expression, but normal expression of markers of earlier migrating neural crest cells) has been proposed to account for PTA in Sema3C (15) and Alk2 mutants (35). The exact mechanism by which Wnt5a could affect CNC cell motility is unknown. Neural crest cells require cell protrusions for locomotion (44). Because calcium transients have been demonstrated to regulate motility of cellular filopodia (45), it is conceivable that a similar $\mathrm{Ca}^{2+}$-mediated mechanism may regulate CNC cell migration or orientation. Wnt5a has been previously implicated in the regulation of migratory behavior of various cell populations $(46,47)$. Although experiments with ectopic Wnt5a suggest a direct effect of Wnt5a on the CNC cells, we cannot exclude the possibility that Wnt5a signal could also be involved in the movement of the cells of the anterior/secondary heart field into the distal conotruncus.

Because Wnt5a is expressed in the pharyngeal mesoderm adjacent to the migrating $\mathrm{CNC}$ cells and within the myocardial cell layer of the OFT itself, we propose a model in which Wnt5a acts as a local morphogen that establishes the appropriate environment and/or signals to CNC cells as they reorganize to form the aortopulmonary septum. Although we do not show a direct evidence of such interactions, the role of local morphogenetic factors, such as TGF- $\beta$ signals, in the assembly of the cardiac OFT has recently been suggested by Choudhary et al. (16). Mice with neural crest-specific deletion of type II TGF- $\beta$ receptor have PTA, yet CNC cell migration, proliferation, and survival are normal. We do not understand the exact mechanism through which these interactions may occur, but possible mechanisms include regulation of targeted migration, cell specification, or time and location of colonization of the OFT by the CNC cells.

Future studies will examine whether Wnt5a mutations may account for OFT defects in humans. Also, as new transgenic mouse lines are generated and more precise labeling techniques of individual cell lineages become available, it will be possible to test the interactions between the secondary/anterior heart field and the CNC cells in a more direct way.

Acknowledgments. The authors thank Dr. Andrew McMahon for providing Wnt5a-deficient mice, Michael Jarcho for technical assistance, and Dr. Michael O'Connor for thoughtful comments on the manuscript.

\section{REFERENCES}

1. Kirby ML, Waldo KL 1990 Role of neural crest in congenital heart disease. Circulation 82:332-340

2. Hoffman JI 2000 Incidence, prevalence, and inheritance of congenital heart disease. In: Moller JH, Hoffman JIE (eds) Pediatric Cardiovascular Medicine. ChurchillLivingstone, Philadelphia, pp 257-262

3. Yamagishi H, Srivastava D 2003 Unraveling the genetic and developmental mysteries of 22q11 deletion syndrome. Trends Mol Med 9:383-389

4. Olson EN, Srivastava D 1996 Molecular pathways controlling heart development. Science 272:671-676

5. Verzi MP, McCulley DJ, De Val S, Dodou E, Black BL 2005 The right ventricle, outflow tract, and ventricular septum comprise a restricted expression domain within the secondary/anterior heart field. Dev Biol 287:134-145

6. Waldo KL, Hutson MR, Ward CC, Zdanowicz M, Stadt HA, Kumiski D, Abu-Issa R, Kirby ML 2005 Secondary heart field contributes myocardium and smooth muscle to the arterial pole of the developing heart. Dev Biol 281:78-90

7. Kelly RG, Brown NA, Buckingham ME 2001 The arterial pole of the mouse heart forms from Fgf10-expressing cells in pharyngeal mesoderm. Dev Cell 1:435-440

8. Fukiishi Y, Morriss-Kay GM 1992 Migration of cranial neural crest cells to the pharyngeal arches and heart in rat embryos. Cell Tissue Res 268:1-8

9. Waldo K, Miyagawa-Tomita S, Kumiski D, Kirby ML 1998 Cardiac neural crest cells provide new insight into septation of the cardiac outflow tract: aortic sac to ventricular septal closure. Dev Biol 196:129-144

10. Yelbuz TM, Waldo KL, Kumiski DH, Stadt HA, Wolfe RR, Leatherbury L, Kirby ML 2002 Shortened outflow tract leads to altered cardiac looping after neural crest ablation. Circulation 106:504-510

11. Waldo KL, Hutson MR, Stadt HA, Zdanowicz M, Zdanowicz J, Kirby ML 2005 Cardiac neural crest is necessary for normal addition of the myocardium to the arterial pole from the secondary heart field. Dev Biol 281:66-77

12. Kirby ML, Waldo KL 1995 Neural crest and cardiovascular patterning. Circ Res 77:211-215

13. Nishibatake M, Kirby ML, Van Mierop LH 1987 Pathogenesis of persistent truncus arteriosus and dextroposed aorta in the chick embryo after neural crest ablation. Circulation 75:255-264

14. Hutson MR, Kirby ML 2003 Neural crest and cardiovascular development: a 20-year perspective. Birth Defects Res C Embryo Today 69:2-13

15. Feiner L, Webber AL, Brown CB, Lu MM, Jia L, Feinstein P, Mombaerts P, Epstein JA, Raper JA 2001 Targeted disruption of semaphorin 3C leads to persistent truncus arteriosus and aortic arch interruption. Development 128:3061-3070

16. Choudhary B, Ito Y, Makita T, Sasaki T, Chai Y, Sucov HM 2006 Cardiovascular malformations with normal smooth muscle differentiation in neural crest-specific type II TGFbeta receptor (Tgfbr2) mutant mice. Dev Biol 289:420-429

17. Kim HJ, Schleiffarth JR, Jessurun J, Sumanas S, Petryk A, Lin S, Ekker SC 2005 Wnt5 signaling in vertebrate pancreas development. BMC Biol 3:23

18. Gordon MD, Nusse R 2006 Wnt signaling: multiple pathways, multiple receptors, and multiple transcription factors. J Biol Chem 281:22429-22433

19. Oishi I, Suzuki H, Onishi N, Takada R, Kani S, Ohkawara B, Koshida I, Suzuki K, Yamada G, Schwabe GC, Mundlos S, Shibuya H, Takada S, Minami Y 2003 The receptor tyrosine kinase Ror2 is involved in non-canonical Wnt5a/JNK signalling pathway. Genes Cells 8:645-654

20. van Gijn ME, Blankesteijn WM, Smits JF, Hierck B, Gittenberger-de Groot AC 2001 Frizzled 2 is transiently expressed in neural crest-containing areas during development of the heart and great arteries in the mouse. Anat Embryol (Berl) 203:185-192

21. Yamaguchi TP, Bradley A, McMahon AP, Jones S 1999 A Wnt5a pathway underlies outgrowth of multiple structures in the vertebrate embryo. Development 126:12111223 
22. Giavini E, Prati M, Vismara C 1981 Morphogenesis of aortic arch malformations in rat embryos after maternal treatment with glycerol formal during pregnancy. Acta Anat (Basel) 109:166-172

23. Person AD, Garriock RJ, Krieg PA, Runyan RB, Klewer SE 2005 Frzb modulates Wnt-9a-mediated beta-catenin signaling during avian atrioventricular cardiac cushion development. Dev Biol 278:35-48

24. Martinsen BJ, Frasier AJ, Baker CV, Lohr JL 2004 Cardiac neural crest ablation alters Id2 gene expression in the developing heart. Dev Biol 272:176-190

25. Ishikawa T, Tamai Y, Zorn AM, Yoshida H, Seldin MF, Nishikawa S, Taketo MM 2001 Mouse Wnt receptor gene Fzd5 is essential for yolk sac and placental angiogenesis. Development 128:25-33

26. Crossley PH, Martin GR 1995 The mouse Fgf8 gene encodes a family of polypeptides and is expressed in regions that direct outgrowth and patterning in the developing embryo. Development 121:439-451

27. Bellusci S, Grindley J, Emoto H, Itoh N, Hogan BL 1997 Fibroblast growth factor 10 (FGF10) and branching morphogenesis in the embryonic mouse lung. Development 124:4867-4878

28. Garg V, Yamagishi C, Hu T, Kathiriya IS, Yamagishi H, Srivastava D 2001 Tbx1, a DiGeorge syndrome candidate gene, is regulated by sonic hedgehog during pharyngeal arch development. Dev Biol 235:62-73

29. Martinsen BJ, Neumann AN, Frasier AJ, Baker CV, Krull CE, Lohr JL 2006 $\mathrm{PINCH}-1$ expression during early avian embryogenesis: implications for neural crest and heart development. Dev Dyn 235:152-162

30. Boot MJ, Gittenberger-De Groot AC, Van Iperen L, Hierck BP, Poelmann RE 2003 Spatiotemporally separated cardiac neural crest subpopulations that target the outflow tract septum and pharyngeal arch arteries. Anat Rec A Discov Mol Cell Evol Biol 275:1009-1018

31. Keck M, Resnik E, Linden B, Anderson F, Sukovich DJ, Herron J, Cornfield DN 2005 Oxygen increases ductus arteriosus smooth muscle cytosolic calcium via release of calcium from inositol triphosphate-sensitive stores. Am J Physiol Lung Cell Mol Physiol 288:L917-L923

32. Linden BC, Resnik ER, Hendrickson KJ, Herron JM, O'Connor TJ, Cornfield DN 2003 Chronic intrauterine pulmonary hypertension compromises fetal pulmonary artery smooth muscle cell O2 sensing. Am J Physiol Lung Cell Mol Physiol 285:L1354-L1361

33. Baranski M, Berdougo E, Sandler JS, Darnell DK, Burrus LW 2000 The dynamic expression pattern of frzb-1 suggests multiple roles in chick development. Dev Biol 217:25-41

34. Hu T, Yamagishi H, Maeda J, McAnally J, Yamagishi C, Srivastava D 2004 Tbx 1 regulates fibroblast growth factors in the anterior heart field through a reinforcing autoregulatory loop involving forkhead transcription factors. Development 131:5491-5502

35. Kaartinen V, Dudas M, Nagy A, Sridurongrit S, Lu MM, Epstein JA 2004 Cardiac outflow tract defects in mice lacking ALK2 in neural crest cells. Development 131:3481-3490

36. Maden M, Horton C, Graham A, Leonard L, Pizzey J, Siegenthaler G, Lumsden A, Eriksson U 1992 Domains of cellular retinoic acid-binding protein I (CRABP I) expression in the hindbrain and neural crest of the mouse embryo. Mech Dev 37:13-23

37. Brown CB, Feiner L, Lu MM, Li J, Ma X, Webber AL, Jia L, Raper JA, Epstein JA 2001 PlexinA2 and semaphorin signaling during cardiac neural crest development Development 128:3071-3080

38. Montcouquiol M, Crenshaw EB3rd, Kelley MW 2006 Noncanonical Wnt signaling and neural polarity. Annu Rev Neurosci 29:363-386

39. Clouthier DE, Hosoda K, Richardson JA, Williams SC, Yanagisawa H, Kuwaki T, Kumada M, Hammer RE, Yanagisawa M 1998 Cranial and cardiac neural crest defects in endothelin-A receptor-deficient mice. Development 125:813-824

40. Waldo KL, Kumiski DH, Wallis KT, Stadt HA, Hutson MR, Platt DH, Kirby ML 2001 Conotruncal myocardium arises from a secondary heart field. Development 128:3179-3188

41. Abu-Issa R, Waldo K, Kirby ML 2004 Heart fields: one, two or more? Dev Biol 272:281-285

42. Mjaatvedt CH, Nakaoka T, Moreno-Rodriguez R, Norris RA, Kern MJ, Eisenberg CA, Turner D, Markwald RR 2001 The outflow tract of the heart is recruited from a novel heart-forming field. Dev Biol 238:97-109

43. Cai CL, Liang X, Shi Y, Chu PH, Pfaff SL, Chen J, Evans S 2003 Isl1 identifies a cardiac progenitor population that proliferates prior to differentiation and contributes a majority of cells to the heart. Dev Cell 5:877-889

44. De Calisto J, Araya C, Marchant L, Riaz CF, Mayor R 2005 Essential role of non-canonical Wnt signalling in neural crest migration. Development 132:2587-2597

45. Lohmann C, Finski A, Bonhoeffer T 2005 Local calcium transients regulate the spontaneous motility of dendritic filopodia. Nat Neurosci 8:305-312

46. Jonsson M, Andersson T 2001 Repression of Wnt-5a impairs DDR1 phosphorylation and modifies adhesion and migration of mammary cells. J Cell Sci 114:2043-2053

47. Kilian B, Mansukoski H, Barbosa FC, Ulrich F, Tada M, Heisenberg CP 2003 The role of Ppt/Wnt5 in regulating cell shape and movement during zebrafish gastrulation. Mech Dev 120:467-476 